\title{
Genomic Resources for Pseudomonas savastanoi pv. phaseolicola Races 5 and 8
}

\section{Bret Cooper ${ }^{\dagger}$ and Ronghui Yang}

Soybean Genomics and Improvement Laboratory, U.S. Department of Agriculture-Agriculture Research Service, Beltsville, MD

\begin{abstract}
Pseudomonas savastanoi pv. phaseolicola causes halo blight disease on Phaseolus vulgaris. Using a long-read DNA sequencing platform, we assembled the genome sequences for $P$. savastanoi pv. phaseolicola races 5 and 8 that have distinguishable avirulent and virulent phenotypes on Phaseolus vulgaris PI G19833, a common bean with an annotated genome sequence. The 12 race 5 assemblies comprise two major 4.5 and $1.4 \mathrm{Mb}$ chromosome-like contigs and 10 smaller contigs. The four race 8 assemblies comprise a major $6.1 \mathrm{Mb}$ chromosome and three smaller contigs. Annotation yielded 5,890 genes for race 5 and 5,919 genes for race 8 . These data will enable the discovery of the genetic and proteomic differences between these two races and allow comparisons to other races for which genomic information already exists.
\end{abstract}

\section{Genome Announcement}

Pseudomonas syringae pv. phaseolicola causes halo blight disease on Phaseolus vulgaris, the common bean (Arnold et al. 2011). At the National Center for Biotechnology Information (NCBI), P. syringae pv. phaseolicola is reclassified as $P$. savastanoi pv. phaseolicola. We will use the NCBI designation forthwith.

In May 2020, on the NCBI website, there were 40 genome assemblies for $P$. savastanoi pv. phaseolicola isolates. At the time, nearly all were fragmented genome assemblies without genome annotations and without gene models except for strain 1448A, which comprises a complete 6.1 Mb chromosome and two plasmids (Joardar et al. 2005). There are at least nine $P$. savastanoi pv. phaseolicola races defined by classical gene-for-gene phenotyping (Taylor et al. 1996b, a), but among the $40 \mathrm{NCBI}$ assemblies, only race 4, race 6 (strain 1448A), and race 7 are clearly represented.

At this time, Phaseolus vulgaris PI G19833 is the only bean with a fully annotated sequenced genome (Schmutz et al. 2014). It is considered a reference model for bean research. We have demonstrated that $P$. savastanoi pv. phaseolicola race 5 (R5) elicits classical severe hypersensitive resistance (immune phenotype) on PI G19833 and that $P$. savastanoi pv. phaseolicola race 8 (R8) produces large water-soaking infections (susceptible phenotype) (Cooper et al. 2020). These races respectively produce the same reactions on Phaseolus vulgaris 'Black Valentine' (Cooper et al. 2020). Both races also are distinguished by their phenotypes on Phaseolus vulgaris 'Canadian Wonder' and 'Guatemala 196-B' (Taylor et al. 1996a, b; Cooper et al. 2020).

${ }^{\dagger}$ Corresponding author: B. Cooper; bret.cooper@ars.usda.gov

Author contributions: B.C. conceived the study, analyzed data, and wrote the paper. R.Y. isolated DNA.

The author(s) declare no conflict of interest.

Accepted for publication 10 December 2020.
Funding

This project was funded by the USDAARS.

\section{Keywords}

bacterial pathogens, microbe-genome sequencing, Phaseolus vulgaris,

Pseudomonas syringae, resistance, susceptibility 
We obtained R5 and R8 from Talo Pastor-Corrales, USDA-ARS, who obtained them from Deidre Fourie, ARC-Grain Crops Institute, Potchefstroom, South Africa, who obtained them from the original collection of John Taylor, maintained at the Warwick Crop Centre, Warwick, United Kingdom (Taylor et al. 1996b). We cultured these isolates and kept them viable at room temperature on King agar B solid medium. Several colonies of each were used to prepare liquid cultures in Luria broth from which we purified DNA using the DNeasy UltraClean Microbial Kit (Qiagen, Hilden, Germany). We contracted Genewiz (South Plainfield, NJ) to sequence the DNA using the PacBio Sequel configuration (Menlo Park, CA). Purified DNA was fragmented and damage/end repaired. Barcoded adaptors were ligated to the DNA fragments. Prepared libraries were pooled together and purified. Sequencing primers were annealed, and sequencing reactions were performed. Demultiplexed subreads were checked for quality, and coverages were estimated. Subreads were random sampled to $200 \times$ coverage before assembly for optimized performance and assembly accuracy. The sequences were then assembled with Canu using default parameters except that the genome size was specified as $6,090,000$ bp (Koren et al. 2017). Merged contigs were circularized, if possible, with Circlator using default parameters (Hunt et al. 2015). Circularized contigs were rotated and the start positions were changed if a gene from a predefined common start gene list was found. All the contigs after merging/circularization were then polished with raw subreads with Arrow in the PacBio software. For R5, there were 117,985 polymerase reads, 733,528 subreads, with a total subread length of $3.4 \times 10^{9}$. The estimated coverage for R5 was $556 \times$. For R8, there were 163,798 polymerase reads, $1,074,514$ subreads, with a total subread length of $4.7 \times 10^{9}$. The estimated coverage for $\mathrm{R} 8$ was $769 \times$. The set of $12 \mathrm{R} 5$ contigs comprised two major 4.5 and $1.4 \mathrm{Mb}$ chromosome-like sequences and 10 smaller sequences with a total contig length of $6,295,462$. The set of four R8 contigs comprised a major $6.1 \mathrm{Mb}$ chromosome sequence and three smaller sequences with a total contig length of 6,304,084.

The final assemblies were annotated with the Prokka prokaryotic genome annotation pipeline (Seemann 2014). Annotation of R5 yielded 5,890 genes, and 5,765 coding sequences (CDS), 67 tRNA, 1 tmRNA, 19 rRNA, 37 ncRNA, 20 regulatory, and 4 misc_feature sequences. Annotation of R8 yielded 5,919 genes, and 5,802 CDS, 66 tRNA, 1 tmRNA, 16 rRNA, 34 ncRNA, 24 regulatory, and 3 misc_feature sequences. BLAST analysis comparing $\mathrm{R} 5$ to $\mathrm{R} 8 \mathrm{CDS}$ revealed that about $88 \%$ of the $\mathrm{R} 5$ sequences had more than $90 \%$ identity to their orthologous $\mathrm{R} 8$ sequences. There also were unique genes to each. R5 encodes a gene for the avirulence protein avrPphF (GSU75_01460) (Tsiamis et al. 2000), whereas R8 does not. Conversely, R8 encodes genes for avrPphB (HopAW1; GS393_00061) and avrPphC (GS393_00060) (Puri et al. 1997; Yucel et al. 1994), whereas R5 does not. Preliminary annotation and categorization revealed that $\mathrm{R} 5$ has twice as many transposon and insertional elements. This may explain, in part, the greater number of contigs for R5 compared with R8.

Genome sequencing for R5 and R8 completes a model system resource needed to study PI G19833 immunity and susceptibility to $P$. savastanoi pv. phaseolicola (Arnold et al. 2011). Unfortunately, PI G19833 is resistant to Bean pod mottle virus (BPMV), which precludes the use of BPMV to study gene function by virus-induced gene silencing. Bean cultivar Black Valentine, however, is susceptible to BPMV, and Black Valentine and PI G19833 share a common Andean bean ancestor (Schmutz et al. 2014). We have demonstrated that the R5 avirulence and R8 virulence phenotypes are the same on Black Valentine as PI G19833. Hence, the BPMV gene silencing system can be used in Black Valentine to study the function of some genes discovered in PI G19833 and their activities toward providing defense to R5 and R8 (Zhang et al. 2013; Cooper et al. 2020). The gene models for R5 and R8 also will facilitate the identification of proteins by mass spectrometry, among other things.

Data and material availability. Genome and protein sequences for R5 and R8 are associated with NCBI BioProject PRJNA598713. R5 sequences are associated with BioSample SAMN13714830 and locus prefix GSU75. R8 sequences are associated with BioSample SAMN13714831 and locus prefix GS393. Raw sequencing subreads are associated with SRA accessions SRR11478898 (R5) and SRR11478897 (R8). 


\section{Literature Cited}

Arnold, D. L., Lovell, H. C., Jackson, R. W., and Mansfield, J. W. 2011. Pseudomonas syringae pv. phaseolicola: From 'has bean' to supermodel. Mol. Plant Pathol. 12:617-627.

Cooper, B., Campbell, K. B., Beard, H. S., Garrett, W. M., and Ferreira, M. E. 2020. The proteomics of resistance to halo blight in common bean. Mol. Plant-Microbe Interact. 33:1161-1175.

Hunt, M., Silva, N. D., Otto, T. D., Parkhill, J., Keane, J. A., and Harris, S. R. 2015. Circlator: Automated circularization of genome assemblies using long sequencing reads. Genome Biol. 16:294.

Joardar, V., Lindeberg, M., Jackson, R. W., Selengut, J., Dodson, R., Brinkac, L. M., Daugherty, S. C., Deboy, R., Durkin, A. S., Giglio, M. G., Madupu, R., Nelson, W. C., Rosovitz, M. J., Sullivan, S., Crabtree, J., Creasy, T., Davidsen, T., Haft, D. H., Zafar, N., Zhou, L., Halpin, R., Holley, T., Khouri, H., Feldblyum, T., White, O., Fraser, C. M., Chatterjee, A. K., Cartinhour, S., Schneider, D. J., Mansfield, J., Collmer, A., and Buell, C. R. 2005. Whole-genome sequence analysis of Pseudomonas syringae pv. phaseolicola 1448A reveals divergence among pathovars in genes involved in virulence and transposition. J. Bacteriol. 187:6488-6498.

Koren, S., Walenz, B. P., Berlin, K., Miller, J. R., Bergman, N. H., and Phillippy, A. M. 2017. Canu: Scalable and accurate long-read assembly via adaptive k-mer weighting and repeat separation. Genome Res. 27:722-736.

Puri, N., Jenner, C., Bennett, M., Stewart, R., Mansfield, J., Lyons, N., and Taylor, J. 1997. Expression of avrPphB, an avirulence gene from Pseudomonas syringae pv. phaseolicola, and the delivery of signals causing the hypersensitive reaction in bean. Mol. Plant-Microbe Interact. 10:247-256.

Schmutz, J., McClean, P. E., Mamidi, S., Wu, G. A., Cannon, S. B., Grimwood, J., Jenkins, J., Shu, S., Song, Q., Chavarro, C., Torres-Torres, M., Geffroy, V.,
Moghaddam, S. M., Gao, D., Abernathy, B., Barry, K., Blair, M., Brick, M. A., Chovatia, M., Gepts, P., Goodstein, D. M., Gonzales, M., Hellsten, U., Hyten, D. L., Jia, G., Kelly, J. D., Kudrna, D., Lee, R., Richard, M. M., Miklas, P. N., Osorno, J. M., Rodrigues, J., Thareau, V., Urrea, C. A., Wang, M., Yu, Y., Zhang, M., Wing, R. A., Cregan, P. B., Rokhsar, D. S., and Jackson, S. A. 2014. A reference genome for common bean and genome-wide analysis of dual domestications. Nat. Genet. 46: 707-713.

Seemann, T. 2014. Prokka: Rapid prokaryotic genome annotation. Bioinformatics 30: 2068-2069.

Taylor, J. D., Teverson, D. M., Allen, D. J., and Pastor-Corrales, M. A. 1996b. Identification and origin of races of Pseudomonas syringae pv. phaseolicola from Africa and other bean growing areas. Plant Pathol. 45:469-478.

Taylor, J. D., Teverson, D. M., and Davis, J. H. C. 1996a. Sources of resistance to Pseudomonas syringae pv. phaseolicola races in Phaseolus vulgaris. Plant Pathol. 45:479-485.

Tsiamis, G., Mansfield, J. W., Hockenhull, R., Jackson, R. W., Sesma, A., Athanassopoulos, E., Bennett, M. A., Stevens, C., Vivian, A., Taylor, J. D., and Murillo, J. 2000. Cultivar-specific avirulence and virulence functions assigned to avrPphF in Pseudomonas syringae pv. phaseolicola, the cause of bean halo-blight disease. EMBO J. 19:3204-3214.

Yucel, I., Slaymaker, D., Boyd, C., Murillo, J., Buzzell, R. I., and Keen, N. T. 1994. Avirulence gene avrPphC from Pseudomonas syringae pv. phaseolicola 3121: A plasmid-borne homologue of avrC closely linked to an avrD allele. Mol. PlantMicrobe Interact. 7:677-679.

Zhang, C., Whitham, S. A., and Hill, J. H. 2013. Virus-induced gene silencing in soybean and common bean. Methods Mol. Biol. 975:149-156. 